\title{
Enhancement of Quality of Secondary Industrial Wastewater Effluent by Coagulation Process: A Case Study
}

\author{
Hossam Altaher, Ahmed Alghamdi \\ Department of Chemical Engineering Technology, Yanbu Industrial College, Yanbu Industrial City, Kingdom of Saudi Arabia. \\ Email: haltaher@hotmail.com
}

Received Augst 17 $7^{\text {th }}, 2011$; revised September $23^{\text {rd }}, 2011$; accepted October $24^{\text {th }}, 2011$.

\begin{abstract}
The local wastewater treatment facility in Yanbu Industrial City receives 24,000 $\mathrm{m}^{3} /$ day of industrial wastewater. This wastewater, mostly from refineries and petrochemical industries, goes through physical, biological and chemical stages of treatment. However, the treated water still fails to pass some of the permissible levels set by governmental agencies. This research paper investigated the enhancement of the treatment processes to reduce the turbidity of the effluent treated water. Ferric chloride, ferrous sulfate, alum and commercial synthetic cationic polymer were tried as coagulants. Different conditions (i.e., pH, temperature, dose, stirring rate) were searched. Ferrous sulfate and polymer reduced the final turbidity to acceptable values with very low doses compared with other coagulant.
\end{abstract}

Keywords: Coagulation, Turbidity, Industrial, Wastewater, Treatment, Polymer

\section{Introduction}

Turbidity consists of suspended material in water, causing cloudy appearance. This cloudy appearance caused by scattering and absorption of light by these particles. The suspended matter may be inorganic or organic. Generally the small size of particles prevents rapid settling of the material and water must be treated to reduce its turbidity. Turbidity can provide food and shelter for pathogens. If not removed, turbidity can promote regrowth of pathogens in the distribution system leading to waterborne disease outbreaks. Although turbidity is not a direct indicator of health risk, numerous studies show a strong relationship between removal of turbidity and removal of protozoa [1].

Treatment for reducing turbidity involves filtration [2], coagulation and flocculation [3]. Effective treatment of turbid water remains a challenge. This is because microbial reduction is decreased or prevented by turbidity particles that reduce access to target microbes or otherwise protect them from inactivation by other mechanisms. Suspended matter in water reduces the microbiocidal efficacy of chlorine and other chemical disinfectants, and it physically shields microbes from the UV radiation, that is responsible for much of its disinfection activity. There is a need to investigate, characterize and implement appropriate physical and physical-chemical technologies for practical and low cost pre-treatment and treatment of water taking into consideration turbid waters of different quality with respect to particle characteristics and their removal efficiencies prior to chlorination [4].

Solids are present in water in three main forms: suspended particles, colloids and dissolved molecules. Suspended particles such as sand, vegetable matter and silt range in size from very large particles down to particles with a typical dimension of $10 \mu \mathrm{m}$. Colloids are very fine particles, typically ranging from $10 \mathrm{~nm}$ to $10 \mu \mathrm{m}$. Dissolved molecules are present as individual molecules or as ions. Dissolved molecules cannot be removed by conventional physical treatment. Thus, the removal of colloids is the main objective and the most difficult aspect in conventional water treatment. Most suspended solids smaller than $0.1 \mathrm{~mm}$ found in water carry negative electrostatic charges. Since, the particles have similar negative electrical charges and electrical forces to keep the individual particles separate, the colloids stay in suspension as small particles. To remove colloids, small particles have to be destabilized first and then they will form larger and heavier flocks which can be removed by conventional physical treatment. This process can be described by clarification mechanism, which includes: coa- 
gulation, flocculation and sedimentation [5].

Alum is the most widely used coagulant in water treatment, because of its proven performance and cost effectiveness. The use of alum as a coagulant increases the aluminum concentration in finished water [6]. The high concentration of aluminum is also of concern because of potential adverse health effects. Aluminum intake into the body has been linked with several possible neuropathological diseases including Alzheimer's disease [7].

An approach to reduce the concentration of residual aluminum in finished water is to use a synthetic polymer or a naturally occurring polyelectrolyte as a coagulant aid with primary coagulant alum. A polyelectrolyte in conjunction with a metal coagulant improves coagulation by accelerating the process of coagulation. The coagulant aid reduces the requirement of alum and improves the physical characteristic of flocs, which results in better quality of treated water [8]. Other coagulants can also be used. These coagulants include ferric salts and synthetic polymers [9]. There has been considerable interest in the development of natural coagulants. By using natural coagulants considerable saving in chemicals and sludge handling cost may be achieved. Chitosan is inexpensive, biodegradable and nontoxic for mammals. Moreover, its molecules have the ability to interact with bacterial surface and are adsorbed on the surface of the cell and stack on the microbial cell surface and forming impervious layer around the cell, leading to the block of the cell [10].

During recent decades research on electricity applied directly in water treatment has progressed well, making it an attractive method for coagulation or clarification of water, usually known as the electro-coagulation/electrochemical method. In this method direct current is passed through aluminum/iron plates suspended in water. This system causes sacrificial electrode ions to move into an electrolyte. Undesirable contaminants are removed either by chemical reaction and precipitation or by causing colloidal materials to coalesce. They are then removed by electrolytic flotation, or sedimentation and filtration. Disinfection is also accomplished by anodic oxidation. The mechanisms of coagulation were similar for electrocoagulation and aluminum salts treatment. The difference is mainly in the way aluminum ions are delivered [11].

Polyelectrolytes are one of the most widely used chemicals serving as coagulants/flocculents in modern water/ wastewater treatment. Their primary advantages are their very low dosing requirement and their applicability over a wide range of $\mathrm{pH}$ compared with alum or other inorganic coagulants/flocculants. Polyelectrolytes are categorized based on their product origin. Natural polyelectrolytes include polymers of biological origin derived from starch, cellulose, and alginates. Synthetic poly- electrolytes consist of single monomers polymerized into a high-molecular-weight substance. The action of polyelectrolytes changes according to their type. Cationic polymers, in which the cations (positive charges) form the polymer, reduce or reverse the negative charges of the precipitate and therefore act as a primary coagulant. Anionic polymers, based on carboxylate ions and polyampholytes, carry primarily negative charges and help in interparticle bridging along the length of the polymer, resulting in three-dimensional particle growth and thereby easy settlement. A third type of polymer, developed from cationic polyelectrolytes of extremely high molecular weight, is capable of offering both coagulation and bridging [12].

The local wastewater treatment facility in Yanbu Industrial City is responsible for the treatment of industrial wastewater collected from the local industrial facilities. Most of these are petroleum refineries and petrochemical facilities. The capacity of treatment facility is 24,000 $\mathrm{m}^{3} /$ day. However, it receives $32,000 \mathrm{~m}^{3} /$ day. This may be a reason of the turbidity of the secondary treated water exceeding the limits set by the governmental agents. Taken into consideration that the treated water after the biological process is not disinfected, there is an urgent need to decrease the turbidity to the lowest possible level to avoid dangerous pollution of the Red Sea. So, a critical need for correction action was necessary. The objective of this research was to enhance the quality of the secondary treated wastewater and reduce the turbidity of the wastewater to the required limit.

\section{Experimental}

\subsection{Materials}

Raw water samples were obtained from the local wastewater treatment facility at Yanbu Industrial City. The samples were collected from the effluent of the industrial wastewater treatment unit. The samples were well agitated before each use. The coagulants used were of analytical grade. The alum was obtained from Panreac Quimica SA (Spain), the ferric chloride from Loba Chemie (India), the ferrous sulfate from TechnoPharmChem (India), and the polymer used was powder cationic polymer M-969 Non-Hazard, Polyelectrolyte dry polymer. This polymer was obtained from Metito Chemical Industrial Ltd. $1 \%$ solutions of these coagulants were prepared by dissolving 10 grams of each coagulant in 1 liter of distilled water. Sodium hydroxide and sulfuric acid were used for adjusting pHs. These two solutions was prepared by dissolving the gram equivalent weight of each in one litre of distilled water.

\subsection{Equipment}

The $\mathrm{pH}$ was measured using pH501, EuTech Instruments. 
The $\mathrm{pH}$ meter was calibrated before use all over the range of $\mathrm{pHs}$ that was utilized. The turbidity was measured using Hach 2100AN Turbidimeter. TDS was monitored using SevenEasy conductivitimeter from Metler Toledo.

\subsection{Coagulation/Flocculation Test}

A conventional jar test apparatus (SLOTEQ flocculation test unit, Model TR10) was employed for the test. It had six stirrers. Every stirrer was controlled individually. All tests were carried out with $500 \mathrm{ml}$ of wastewater in 1 -liter beaker. All tests were performed at room temperature unless otherwise mentioned.

Optimum $\mathrm{pH}$ was determined by adjusting of $500 \mathrm{ml}$ aliquot of wastewater at different $\mathrm{pHs}$ using sulfuric acid and sodium hydroxide. To each wastewater sample the same dose of coagulant was added. A fast stirring of 250 rpm was applied for 2 minutes. The stirring speed was then reduced to $50 \mathrm{rpm}$ for 15 minutes. At the end of the slow speed period, the mixing was stopped and the formed flocs were left to settle down for 15 minutes. The samples to be tested were taken $2 \mathrm{~cm}$ from the top of the water level in the beaker. Turbidity, total dissolved solids and $\mathrm{pH}$ were determined.

The effect of coagulant dose, rate of rapid and slow stir-ing were determined similarly with change of appropriate conditions. To examine the effect of temperature a sample was warmed over the hot plate to reach the required temperature and another sample was placed inside the incubator to reach the required cold reduced temperature.

To test the settling rate, 1-liter sample was treated with the coagulant, rapidly-stirred for 2 minutes, slow-stirred for 15 minutes and placed in 1-liter cylinder. The level of the flocs in the cylinder was monitored with time for 30 minutes.

\section{Results and Discussion}

\subsection{Effect of Coagulant Dose}

Figure 1 indicates the relation between the used coagulant dose and its effect on the turbidity removal efficiency which was calculated according to the following equation:

Turbidity removal efficiency $\%=[($ initial turbidity final turbidity)/initial turbidity]*100

The figure indicates different effects and behaviors of coagulants. The increase of ferric chloride dose from 100 $\mathrm{mg} / \mathrm{l}$ to $1200 \mathrm{mg} / \mathrm{l}$ resulted in an increase of turbidity removal efficiency from $86 \%$ to $97 \%$. However, only $200 \mathrm{mg} / \mathrm{l}$ were enough to reduce the turbidity to the permissible turbidity level set by Royal Commission (15 NTU). Considerable decrease in the final $\mathrm{pH}$ value was also observed. The final $\mathrm{pH}$ was function in the coagu-

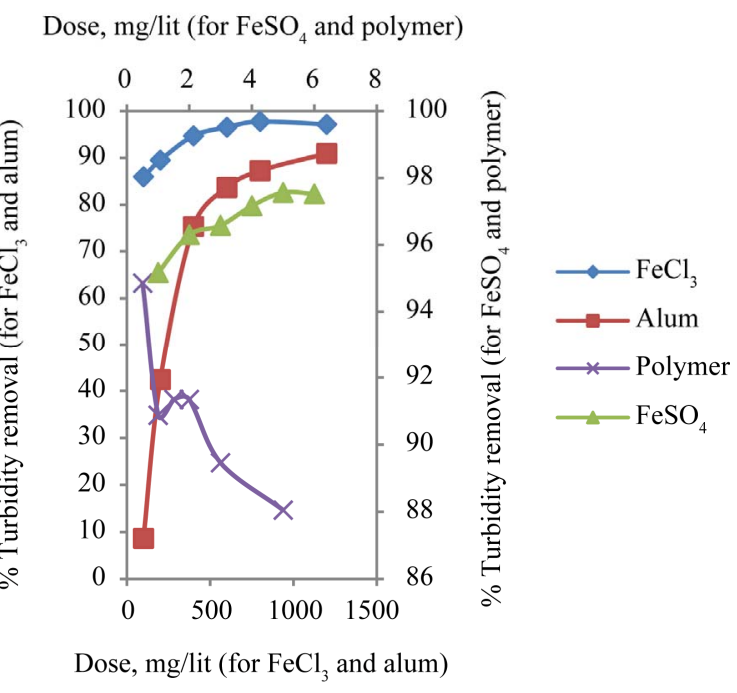

Figure 1. Effect of coagulant dose on turbidity removal efficiency. The $\mathrm{pH}$ of wastewater was 7.9 , initial turbidity was $138 \mathrm{NTU}$, and initial TDS was $11.15 \mathrm{mg} / \mathrm{l}$.

lant dose. With a lowest $\mathrm{pH}$ value of 5.3 obtained when applied $1200 \mathrm{mg} / \mathrm{l}$ of the coagulant. A relation of dose and final TDS was also noticed. Increasing the dose increased the TDS of the sample. The reason may be attributed to the coagulant itself which represents an added salt to the original sample. The effect of ferrous sulfate was quite different. The preliminary experiments indicated that high doses of this coagulant $(\geq 400 \mathrm{mg} / \mathrm{l}$ ) resulted in increase in turbidity of the final sample. The dose range applied for this coagulant was reduced to be between $1-6 \mathrm{mg} / \mathrm{l}$. In this range the turbidity removal efficiency was between $95 \%$ and $97.5 \%$. The lowest dose that was used $(20 \mathrm{mg} / \mathrm{l})$ was enough to drop the final turbidity to $6.9 \mathrm{NTU}$, a value well below the permissible level. The final TDS of the samples increased to an average value of $16.4 \mathrm{mg} / \mathrm{l}$ compared to an initial TDS of $11.31 \mathrm{mg} / \mathrm{l}$. The final $\mathrm{pH}$ of all doses was 11.2. This value is high compared with that set by governmental agencies for treated wastewater ( $\mathrm{pH} 6-9)$ which requires more treatment to reduce this $\mathrm{pH}$ value to accepted discharge limit. The polymer showed comparable turbidity removal efficiency to that was obtained by ferrous sulfate. $1 \mathrm{mg} / 1$ of the polymer dropped the turbidity to 7.7 NTU. The polymer had other important effects. It did not change the $\mathrm{pH}$ of the treated water nor the final TDS. All the flocs gathered to form 4 big flocs during the slow stirring period. That means no need for settling period. The alum showed the weakest treating ability only at a very high dose $(1200 \mathrm{mg} / \mathrm{l})$ the turbidity dropped to a value lower than permissible level.

\subsection{Effect of Wastewater $\mathbf{p H}$}

Figure 2 indicates the effect of $\mathrm{pH}$ on turbidity removal 


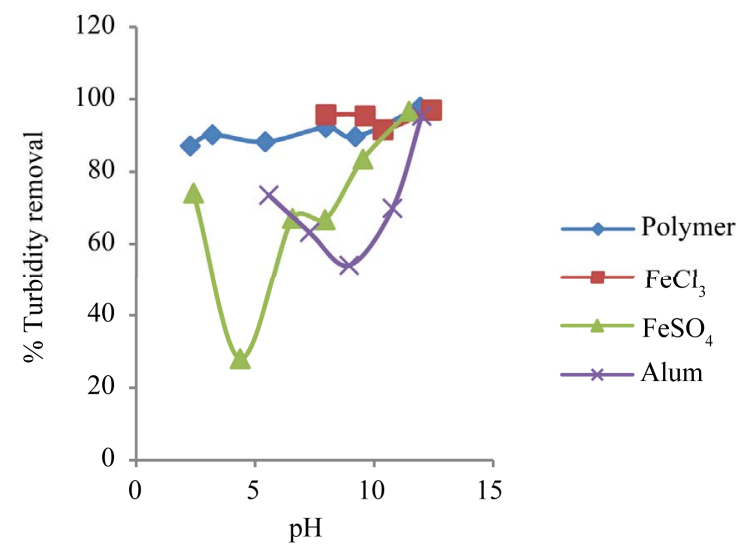

Figure 2. Effect of initial $\mathrm{pH}$ of wastewater on turbidity removal efficiency. Initial turbidity was $138 \mathrm{NTU}$, and initial TDS was $11.15 \mathrm{mg} / \mathrm{l}$.

efficiency. The two acidic $\mathrm{pH}$ values (2.08 and 5.52) that were tested for ferric chloride resulted in very high increase in turbidity. The turbidity increased by factors of 17.4 and $32 \%$, respectively, instead of decreasing at these acidic values. The explanation may be the need for alkalinity for precipitation of ferric hydroxide to take place. The possible reactions responsible for coagulations are as follows:

$$
\begin{gathered}
2 \mathrm{FeCl}_{3}+6 \mathrm{HCO}_{3}^{-} \rightarrow 2 \mathrm{Fe}(\mathrm{OH})_{3}(\downarrow)+6 \mathrm{Cl}^{-}+6 \mathrm{CO}_{2} \\
\mathrm{FeSO}_{4}+2 \mathrm{HCO}_{3}^{-} \rightarrow \mathrm{Fe}(\mathrm{OH})_{2}(\downarrow)+\left(\mathrm{SO}_{4}\right)^{-}+2 \mathrm{CO}_{2} \\
\mathrm{Al}_{2}\left(\mathrm{SO}_{4}\right)_{3}+6 \mathrm{HCO}_{3}^{-} \rightarrow \\
2 \mathrm{Al}(\mathrm{OH})_{3}(\downarrow)+3\left(\mathrm{SO}_{4}\right)^{2-}+6 \mathrm{CO}_{2}
\end{gathered}
$$

In acidic medium, the bicarbonate species required for such reaction are not available. Consequently, no precipitation would occur. Except for polymer, all other coagulants showed weak to mild coagulation efficiency at acidic values. This can be interpreted using the previous reactions. It is clear from the stoichiometry of the reactions that there is a different need for alkalinity for precipitation of hydroxides to take place, with alum having the highest need (6 moles of alkalinity for every mole of alum).

In the basic region, the ferric chloride indicated excellent removal efficiency. At $\mathrm{pH} 7.95$ (original $\mathrm{pH}$ of the wastewater), ferric chloride showed the highest efficiency ( $96 \%$ equivalent to final turbidity of 5.8 ). An important point must be taken into consideration which is the dose. The ferric chloride dose that was used to reach this value was $800 \mathrm{mg} / \mathrm{l}$, compared to a dose of $100 \mathrm{mg} / \mathrm{l}$ for ferrous sulfate and a dose of $20 \mathrm{mg} / \mathrm{l}$ that produced $97 \%$ and $92 \%$ removal efficiency, respectively. It can be also noted all coagulant showed the same removal effi- ciency at very high $\mathrm{pH}$ value. (nearly at $\mathrm{pH}$ value of 12 ). The reason was not just the coagulant in this case. It was noticed that adjusting the $\mathrm{pH}$ at this value resulted in precipitation, even without adding any coagulant. The enhancement of removal efficiency at that high $\mathrm{pH}$ may be attributed to the formed precipitate that might have a sweeping action to the suspended solids present in wastewater, thus decreasing turbidity.

There is no single $\mathrm{pH}$ region that has been agreed upon by researcher as the optimum $\mathrm{pH}$ region for coagulation. Wang et al. [13] suggested the $\mathrm{pH}$ region of $3-8$. Other researchers [14-16] suggested $\mathrm{pH}$ region (4 - 5.4) if using ferric salts as coagulants and water contains organic colloids.

The $\mathrm{pH}$ value was found to have a pronounced effect on the final TDS of the sample. Figure 3 represents such relation. The general trend for the relation between $\mathrm{pH}$ and TDS is the decrease of TDS with increasing the $\mathrm{pH}$ up to approximate $\mathrm{pH}$ value of 7.95 (initial $\mathrm{pH}$ of wastewater), followed by increase of TDS with further increase in $\mathrm{pH}$. The reason is attributed to the sodium hydroxide and sulfuric acids that were added to increase or decrease the $\mathrm{pH}$. Both of them increase the TDS of the wastewater sample.

\subsection{Effect of Wastewater Temperature}

Figure 4 represents the effect of temperature on removal efficiency. The temperature range investigated $\left(15^{\circ} \mathrm{C}-\right.$ $48^{\circ} \mathrm{C}$ ) represents the temperature range in Yanbu Industrial City between Winter and Summer. The figure indicates negligible effect on turbidity removal in case of ferric chloride, ferrous sulfate and polymer. The effect of temperature is considerable using alum.

The lowest turbidity removal using this coagulant was achieved at $25^{\circ} \mathrm{C}(70.5 \%)$. The efficiency increased to

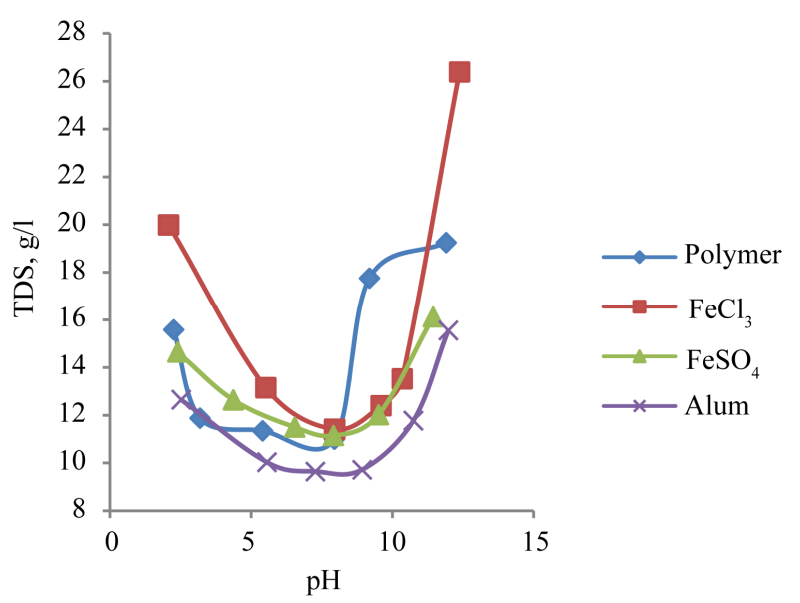

Figure 3. Effect of initial pH of wastewater on final TDS of wastewater. Initial turbidity was 138 NTU, and initial TDS was $11.15 \mathrm{mg} / \mathrm{l}$ at room temperature. 


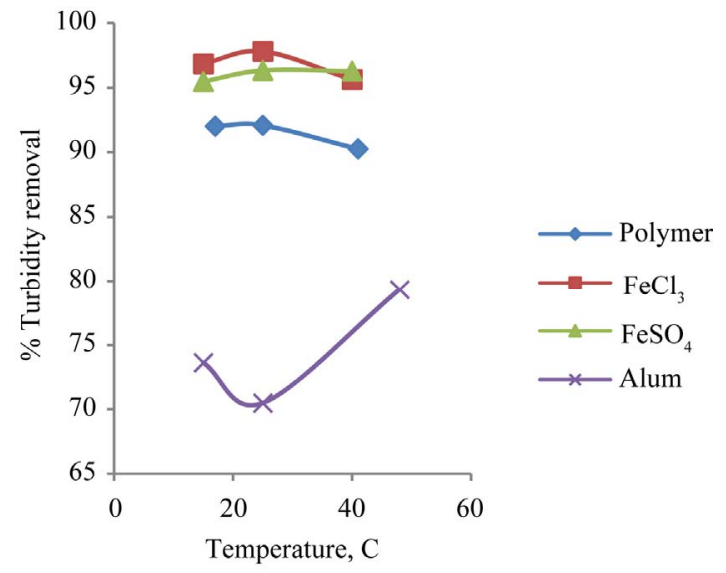

Figure 4. Effect of wastewater temperature on turbidity removal efficiency.

$73.5 \%$ at $15^{\circ} \mathrm{C}$ and to $79.4 \%$ at $48^{\circ} \mathrm{C}$. Fitzpatrick and et al. [17] studied the effect of temperature on flocculation using different coagulant. However, their results are different. The coagulation using alum was better at higher temperature. They attributed that to breakage of flocs at low temperatures. Bratby [1] related the effect of temperature to the mechanism of coagulation. He mentioned that this effect is pronounced in case of enmeshment mechanism and less severe in case of adsorption-type mechanism. Guan et al. [18] reported that the turbidity removal efficiency increased gradually by increasing temperature.

\subsection{Effect of Stirring Rate}

The effect of stirring rate on the turbidity removal process for both rapid and slow stages are represented by Figures 5 and 6, respectively. It is evident from figures that the stirring rate does not have any effect on the efficiency of the removal process. Hanhui et al. [5] had similar results. They proposed a relation between efficiency of flocculation with type of flocculants. In case of organic compounds neither stirring time nor stirring intensity affects coagulation-flocculation excessively. The results of this experiment suggest combining the coagulation and flocculation in one process with stirring for reasonable time (15 minutes). This procedure will save a lot of power.

\subsection{Settling Test}

Figure 7 presents the settling rate of flocs formed by different coagulants. The plot representing the sedimentation of flocs formed by polymer is not represented here. As was mentioned before, all the flocs that were formed consolidated to form 4 big flocs that floated at the surface of the sample. That had taken place within three minutes of the slow stirring process. Figure 7 indicates

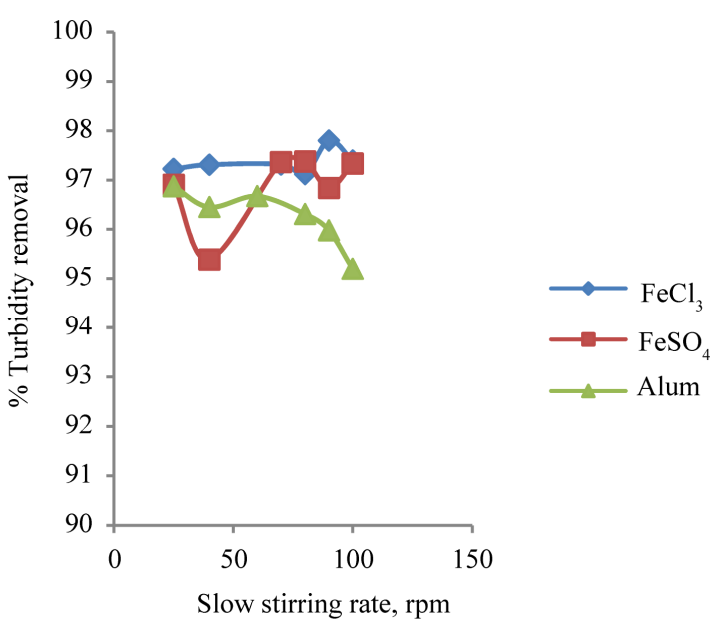

Figure 5. Effect of slow stirring rate on turbidity removal efficiency. Initial turbidity was 138 NTU, initial pH was 7.9 and initial TDS was $11.15 \mathrm{mg} / \mathrm{l}$.

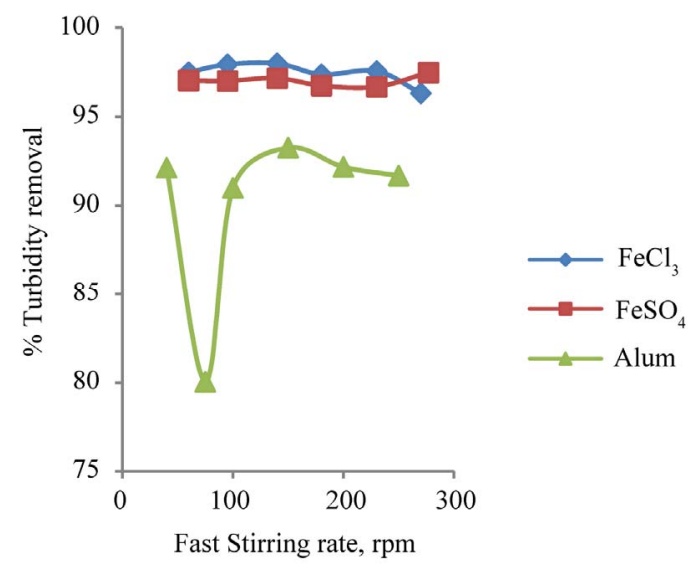

Figure 6. Effect of rapid stirring rate on turbidity removal efficiency. Initial turbidity was 138 NTU, initial pH was 7.9 and initial TDS was $11.15 \mathrm{mg} / \mathrm{l}$.

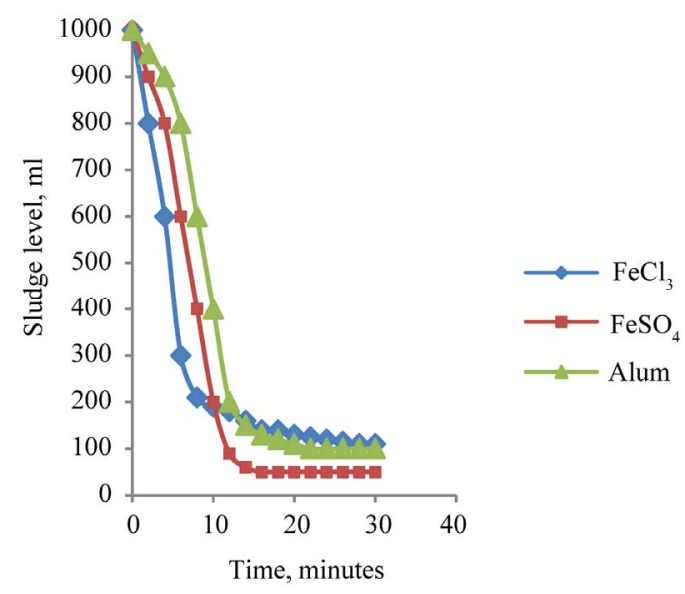

Figure 7. Sludge settling rate. Initial turbidity was 138 NTU, initial $\mathrm{pH}$ was 7.9 and initial TDS was $11.15 \mathrm{mg} / \mathrm{l}$. 
that ferrous sulfate-flocs have the better settlabilty among other flocs. Within 15 minutes the sludge reached its lowest volume compared to 22 and 28 minutes for alum and ferric chloride, respectively. The final sludge volume is another indication about the excellent characteristics of ferrous sulfate as a coagulant. This volume was $50 \mathrm{ml}$ compared to 100 and $110 \mathrm{ml}$ for alum and ferric chloride respectively. The sludge volume index (SVI) for the three coagulants are 25,55 and $50 \mathrm{ml} / \mathrm{l}$, respectively indicate good settling properties.

\section{Conclusions and Recommendations}

The removal efficiency of turbidity from industrial wastewater was experimentally investigated using coagulation technique. Four different coagulants were tested. The temperature did not have a preannounced effect on the coagulation process. The $\mathrm{pH}$ of the wastewater had an important effect on turbidity removal efficiency. The highest removal efficiency was found at higher $\mathrm{pH}$. Even without the addition of coagulant a considerable part of the turbidity would precipitate at elevated $\mathrm{pH}$. The Stirring rate also does not have an effect either. Consequently, the slow and fast steps of stirring can be consolidated in just one step with moderate velocity to save money and time. Ferrous sulfate and polymer were found to be the best polymers. Even at very low doses (in the range of $1-5 \mathrm{mg} /$ lit) the turbidity was reduced to much lower than that required by the governmental agencies. The settling rate for ferrous sulfate was 15 minutes compared to 4 minutes for the polymer. The jar test must be applied regularly to keep up with the continuous changes of the properties of the received industrial wastewater which ensures good quality of the treated water.

\section{Acknowledgements}

The authors are grateful to the local wastewater treatment facility for supplying the industrial wastewater, and polymer used in this work. The authors would like to thank Mr. AbdelRahman Mohanna and Mr. Samy Jaber for their help through this work.

\section{REFERENCES}

[1] J. Bratby, "Coagulation and Flocculation in Water and Wastewater Treatment," Second Edition, IWA Publishing, London, 2006.

[2] O. Nkwonta, O. Olufayo, G. Ochieng, J. Adeyemo and F. Otieno, "Turbidity Removal: Gravel and Charcoal as Roughing Filtration Media," South African Journal of Science, North America, Vol. 106, No. 11-12, 2011, pp. $1-5$.

[3] D. H. Bache and R. Gregory, "Flocs in Water Treatment," IWA Publishing, London, 2007.

[4] H. Sarparastzadeh, M. Saeedi, F. Naeimpoor and B.
Aminzadeh, "Pretreatment of Municipal Wastewater by Enhanced Chemical Coagulation," International Journal of Environmental Research, Vol. 1, No. 2, 2007, pp. 104-113.

[5] H. H. Zhan, X. Q. Zhang and X. H. Zhan, "Coagu-Flocculation Mechanism of Flocculant and Its Physical Model," 2004 ECI Conference on Separations Technology VI: New Perspectives on Very Large-Scale Operations, Vol. Rp3, Article 8, 2004.

[6] P. Niquette, F. Monette, A. Azzouz and R. Hausler, "Impacts of Substituting Aluminum-Based Coagulants In Drinking Water Treatment," Water Quality Research Journal of Canada, Vol. 39, No. 3, 2004, pp. 303-310.

[7] A. Aghapour and A. Mohammadi, "Investigating the Coagulation Efficiency of Paci In Reduction Of Water Turibidty in Shahrchay River in City of Orumieh and Its Health Effects," Health System Research, North America, Vol. 6, March 2011. Accessed on 09 June 2011. http://www.jhsr.ir/index.php/jhsr/article/view/40

[8] P. K. Raghuwanshi, M. Monika, A. J. Sharma, H. S. Malviya and S. Chaudhari, "Improving Filtrate Quality Using Agrobased Materials as Coagulant Aid," Water Quality Research Journal of Canada, Vol. 37, No. 4, 2002, pp. 745-756.

[9] S. A. Muyibi, A. H. M. Birima, T. A. Mohammed and M. J. M. M. Noor, "Conventional Treatment of Surface Water Using Moringa Oleifer Seeds Extract as a Primary Coagulant," IIUM Engineering Journal, Vol. 5, No. 1, 2004, pp. 25-35.

[10] B. Bina, M. H. Mehdinejad, M. Nikaeen and H. M. Attar, "Effectiveness of Chitosan as Natural Coagulant Aid in Treating Turbid Water," Iranian Journal of Environmental Health Science \& Engineering, Vo. 6, No. 4, 2009, pp. 247-252.

[11] A. R. Rahmani, "Removal of Water Turbidity by the Electrocoagulation Method," Journal of Research in Health Sciences, Vol. 8, No. 1, 2008, pp. 18-24.

[12] E. E. Chang, P. C. Chiang, W. Y. Tang, S. H. Chao and H. J. Hsing, "Effects of Polyelectrolytes on Reduction of Model Compounds via Coagulation," Chemosphere, Vol. 58, No. 8, 2005, pp. 1141-1150. doi:10.1016/j.chemosphere.2004.08.008

[13] Z. P. Wang, Z. Zhang., Y. J. Lin, N. S. Deng, T. Tao and K. Zhuo, "Landfill Leachate Treatment by a CoagulationPhotooxidation Process," Journal of Hazardous Mater, Vol. 95, No. 1-2, 2002, pp. 153-159.

[14] D. B. Babcock and P. C. Singer, "Chlorination and Coagulation of Humic and Fulvic Acids," Journal of the American Water Works Association, Vol. 71, 1979, pp. 149-152.

[15] M. L. Semmens and T. K. Field, "Coagulation: Experiences in Organics Removal," Journal of the American Water Works Association, Vol. 72, No. 8, 1980, pp. 476-483.

[16] F. C. Blanc and R. Navia, "Treatment of Diary Wastewater by Chemical Coagulation," Proceedings of the Industrial Waste Conference, 45th, West Lafayette (Indiana), 
8-10 May 1990, pp. 681-689.

[17] C. S. Fitzpatrick, E. Fradin and J. Gregory, "Temperature Effects on Flocculation, Using Different Coagulants," Water Science and Technology, Vol. 50, No. 12, 2004, pp. 171-175.
[18] D. Guan, Z. Zhang, X. Li and H. Liu, "Effect of pH and Temperature on Coagulation Efficiency in a North-China Water Treatment Plant," Advanced Materials Research, Vol. 243-249, 2001, pp. 4835-4838. 